\title{
Morphology of the Cervical Spine Alignment in Scheuermann's Disease
}

\author{
Piotr Janusz ${ }^{1 *}$, Marcin Tyrakowski ${ }^{2}$ and Tomasz Kotwicki ${ }^{1}$ \\ ${ }^{1}$ Department of Spine Disorders and Pediatric Orthopedics, Poznan University of Medical Sciences, Poznan, Poland \\ ${ }^{2}$ Department of Spine Disorders and Orthopedics, The Centre of Postgraduate Medical Education in Warsaw, Poland \\ *Corresponding author: Piotr Janusz, Department of Spine Disorders and Pediatric Orthopedics, Poznan University of Medical Sciences, Poznan, Poland
} Submission: 韭 February 05, 2018; Published: 眥 February 08, 2019

\begin{abstract}
Introduction: Scheuermann's disease (SD) is a one of the most common structural hyperkyphosis of the spine in adolescents. Two types of SD are distinguished, typical in the thoracic spine (SDT) and atypical in the thoracolumbar spine (SDTL). It differently affects the cervical spine alignment. The aim of this study was to evaluate the morphology of the cervical part of the vertebral column in SD patients and an analysis of the possible differences between the SDT and SDTL.

Methods: Eighty-six patients with SD (52 males and 34 females), aged: $16.3 \pm 3.7$ years were included into the study. On standing lateral radiographs the cervical spine alignment was classified as lordotic, straight, sigmoid or kyphotic according to the morphological classification. The following parameters were measured: measurements were made C2-7 cervical lordosis (CL), T5-T12 thoracic kyphosis (TK), L1-L5 lumbar lordosis (LL), T10-L2 thoracolumbar kyphosise (TLK), cervical sagittal vertical axis (cSVA). All the parameters were compared between SDT and SDTL groups
\end{abstract}

Results: There were 48 SDT and 38 SDTL patients. There were 32 males and 16 females in the SDT group versus 20 males and 18 females in STDL group, $\mathrm{p}=0.2714$. The alignment of the cervical spine was lordotic in $56.2 \%$ SDT and 34.2\% SDTL, straight in 37.5\% SDT and 36.8\% SDTL, kyphotic in $4.2 \%$ SDT and $15.8 \%$ SDTL and sigmoid in $2.1 \%$ SDT and $13.2 \%$ SDTL, $\mathrm{p}=0.0289$. CL was greater in SDT $-19.8^{\circ}$ than in SDTL-8.5 $5^{\circ}, \mathrm{p}=0.0089$. There was no significant difference in cSVA 16.9mm in SDT vs. 12.9 in SDTL, $\mathrm{p}=0.2599$.

Conclusion: The type of the Scheuermann's disease has an impact on the cervical spine morphology. There is a higher tendency to the kyphotic and the sigmoid cervical spine alignment in the thoraco-lumbar type than in the thoracic type of Scheuermann disease.

Keywords: Scheuermann's disease; Juvenile kyphosis; Scheuermann's kyphosis; Cervical spine alignment; Spine alignment; Scheuermann disease; Morphological classification; Cervical spine morphology

Abbreviations: SD: Scheuermann's Disease; SDT: Thoracic localization of the Scheuermann's Disease; SDTL: Thoracolumbar Localization of the Scheuermann's Disease; CL-C2-C7: Cervical Lordosis; TK-T5-T12: Thoracic Kyphosis; LL-L1-S1: Lumbar Lordosis; TLK-T10-L2: Thoracolumbar Kyphosis; cSVA: Cervical Sagittal Vertical Axis

\section{Introduction}

Scheuermann's disease (SD) is a one of the most common structural hyperkyphosis of the spine in adolescents [1]. The prevalence of the disease is reported $0.4 \%-8 \%$ of population [24]. The diagnosis of SD is based on radiological findings. The most important finding is a wedging of vertebrae. Other structural changes may be found in the radiological examination: irregularities of the vertebral endplates, Schmorl nodes, narrowing of the disc spaces, and lengthening of the vertebral bodies [5]. There are several diagnostic classifications for establishing the diagnosis of $\mathrm{SD}$, differing in the number of affected vertebrae and presence of additional findings. However, most authors still use the diagnostic criteria introduced by Sorensen $[5,6]$.

Typical for SD structural kyphosis is altering adjacent segments of the spine, causing compensatory response in the sagittal plane.
Thus, in SD global sagittal alignment of the spine is impaired $[7,8]$. The spine sagittal balance was investigated in SD. The spinopelvic radiological parameters, spinal segments and posture were described and relationships between them were established [9-13].

Two types of SD are distinguished, depending on localization of the affected vertebrae. More common localization is thoracic presentation of the disease (SDT), which is called "typical". The other type of SD is thoracolumbar localization (SDTL) called "atypical" [4]. The characteristic changes for SD were described in vertebral column alignment in the cervical spine. The differences between SDT and SDTL were evaluated and comprehensive analysis was performed $[7,8,14]$. However, to our knowledge there is no study describing the morphological classification of the cervical spine alignment in Scheuermann's disease. 
The aim of this study was to evaluate the morphology of the cervical part of the vertebral column in SD patients and an analysis of the possible differences between the SDT and SDTL.

\section{Methods}

Retrospective analysis of patients with SD treated in our clinic between June 2012 and June 2016 was performed. In each case diagnosis of SD was established according to Sorensen`s radiological criteria with irregularities of the vertebral endplates or presence of Schmorl's nodes $[5,6,15]$. Patients with a history of prior spinal surgeries, spinal pathologies other than SD and kyphosis originated from other reasons than SD were excluded from the study. The institutional Review Board approval was obtained. None of the patients had clinical symptoms attributable to the cervical spine.

Eighty-six cases were enrolled into the study, 34 females and 52 males, in the mean age of $16.3 \pm 3.7$ years (range: $11.6-31$ years). In all cases standing long-cassette lateral digital radiographs were taken according to standardized protocol. The radiographs covered pelvis with the hips, the whole spine and the scull to the level of the external auditory meatus and the lower margin of the orbit. Patients were in standing natural position, with horizontal gaze. The shoulders were flexed $30^{\circ}-45^{\circ}$ and the elbows were comfortable flexed with the hands resting on a support. Hips and knees were in full extension [7].

The morphological classification of the cervical spine was assessed according to method proposed by Ohara et al. [16] in the following manner. The distance between the centroids of the C3-C6 vertebrae and the line connecting the midpoints C2 inferior end plate and C7 superior end plate was constructed (Figure 1). The alignment was then classified as lordotic when all centroids were lordotic and at least one of the centroids was outlaying more than $2 \mathrm{~mm}$, straight when all centroids were closer to the line than $2 \mathrm{~mm}$, sigmoid when some of the centroids were lordotic, and some kyphotic and at least one was outlaying more than $2 \mathrm{~mm}$, or kyphotic when all of the centroids were kyphotic and at least one was outlaying more than $2 \mathrm{~mm}$ (Figure 1).

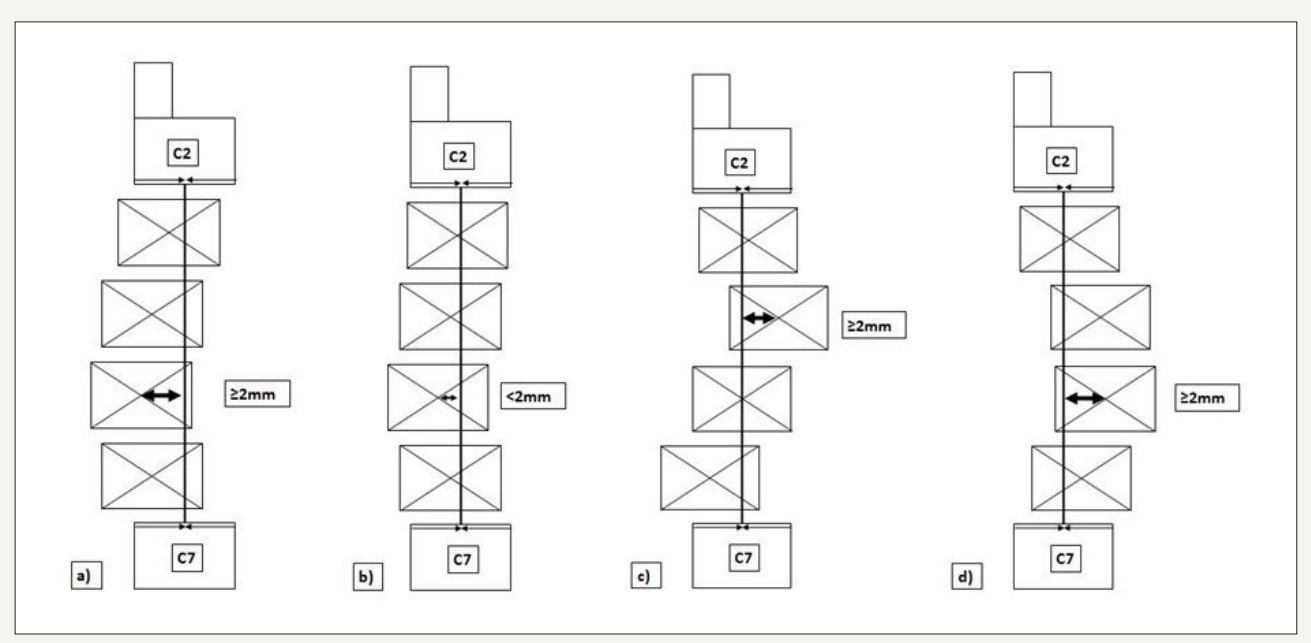

Figure 1: Morphological classification of the cervical spine alignment according to Ohara et al. [16]. a) Lordotic spine, b) Straight spine, c) Sigmoid spine, d) Kyphotic spine. See text for explanation.

The following radiological were measured of each of the patients:

1. C2-C7 Cervical lordosis (CL)-the angle between the inferior endplate of $\mathrm{C} 2$ and the inferior endplate of $\mathrm{C} 7$;

2. Cervical sagittal vertical axis (cSVA) - the distance between plumb line from the center of the $\mathrm{C} 2$ dens and the centroid of $\mathrm{C} 7$;

3. Thoracic kyphosis (TK) - the angle between the superior endplate of T5 and the inferior endplate of T12;

4. Lumbar lordosis (LL) - the angle between the superior endplate of the L1 vertebra and the endplate of S1 measured with Cobb method;

5. Thoraco-lumbar kyphosis (TLK)-the angle between the superior end plate of the T10 vertebra and the inferior end plate of the $\mathrm{L} 2$ vertebra.
6. Patients were divided into two subgroups according to the location of the apex of the kyphosis. Patients with apex at T10 and above were included to the SDT subgroup and patients with the apex located below T10 were included to SDTL subgroup $[7,8]$.

Lordotic angle was noted as negative value and kyphotic angle was noted as positive value for all of the relevant parameters. All the radiographs were measured using Surgimap Spine Software (Surgimap, New York, USA) by an orthopedic spine surgeon with ten years of experience.

For each parameter mean values, standard deviation and range were calculated. Normal distribution of data was analyzed with the Shapiro-Wilk test. The comparison between SDT and SDTL was performed with the unpaired t-test and Mann-Whitney test. The distribution of the results of the morphological classification was performed with $\mathrm{Chi}^{2}$. The p-level of 0.05 was considered significant. Statistical analysis was made using MedCalc 12.7.8.0. 


\section{Results}

There were 48 patients with SDT in the mean age of $16.3 \pm 4.1$ years and 38 with SDTL in the mean age of $16.3 \pm 1.8$ years. There was no significant difference in age between the groups, $\mathrm{p}=0.9935$. There were 32 males and 16 females in the SDT group versus 20 males and 18 females in STDL group with no significant difference between the subgroups, $\mathrm{p}=0.2714$.

Table 1: The radiological parameters of the spine sagittal alignment of SDT and SDTL patients.

\begin{tabular}{|c|c|c|c|}
\hline & SDT & SDTL & P-value \\
\hline & $\mathrm{N}=48$ & $\mathrm{~N}=38$ & \\
\hline Cervical lordosis $\left({ }^{\circ}\right)$ & $\begin{array}{l}-19.4 \pm 17.3 \\
(-67 \div 10)\end{array}$ & $\begin{array}{l}-8.5 \pm 16.1 \\
(-43 \div 34)\end{array}$ & $0.0089^{1}$ \\
\hline cSVA (mm) & $\begin{array}{l}16.9 \pm 15.5 \\
(-15 \div 48)\end{array}$ & $\begin{array}{c}12.9 \pm(13.9) \\
(-36 \div 34)\end{array}$ & $0.2599^{2}$ \\
\hline $\begin{array}{c}\text { Thoracic kyphosis } \\
\text { T5-T12 }\left(^{\circ}\right)\end{array}$ & $\begin{array}{l}58.4 \pm 10.8 \\
(40 \div 86)\end{array}$ & $\begin{array}{l}54.0 \pm 13.8 \\
(26 \div 89)\end{array}$ & $0.1012^{2}$ \\
\hline $\begin{array}{l}\text { Thoraco-lumbar } \\
\text { junction } \\
\text { Th10-L2 }\left(^{\circ}\right)\end{array}$ & $\begin{array}{l}2.1 \pm 12.4 \\
(-32 \div 35)\end{array}$ & $\begin{array}{l}30.6 \pm 15.6 \\
(-1 \div 78)\end{array}$ & $0.0001^{2}$ \\
\hline $\begin{array}{l}\text { Lumbar lordosis } \\
\qquad \text { L1-L5 }\left(^{\circ}\right)\end{array}$ & $\begin{array}{l}-53.1 \pm 9.7 \\
(-74 \div-29)\end{array}$ & $\begin{array}{l}-45.7 \pm 14.1 \\
(-83 \div-16)\end{array}$ & $0.0057^{2}$ \\
\hline
\end{tabular}

${ }^{1}$ Mann-Whitney test, ${ }^{2}$ t-test, SDT thoracic form of the Scheuermann's disease, SDTL thoraco-lumbar form of the Scheuermann's disease, cSVA -cervical sagittal vertical axis; significant differences are marked in bold.

Table2: Morphological classification of SDT and SDTL patients.

\begin{tabular}{|c|c|c|c|}
\hline & SDT & SDTL & P-Value \\
\hline Morphological classification & $\mathrm{N}=48$ & $\mathrm{~N}=38$ & $0.0289^{1}$ \\
\hline Lordotic & $56.2 \%$ & $34.2 \%$ & \\
\hline Straight & $37.5 \%$ & $36.8 \%$ & \\
\hline Kyphotic & $4.2 \%$ & $15.8 \%$ & \\
\hline Sigmoid & $2.1 \%$ & $13.2 \%$ & \\
\hline
\end{tabular}

${ }^{1} \mathrm{Chi}^{2}$ test, SDT thoracic form of the Scheuermann's disease, SDTL thoraco-lumbar form of the Scheuermann's disease.

There were significant differences between SDT and SDTL patients in the following parameters: CL, TLK and LL with $\mathrm{p}=0.0089$, $p=0.0001$ and $p=0.0057$, respectively. The differences in TK and cSVA between SDT and SDTL were not significant. The detailed analysis of the radiological parameters is presented in Table 1. There was significant difference in distribution of the morphological classification of the cervical spine alignment between SDT and SDTL, $p=0.0289$. The prevalence of the morphological cervical spine alignments is presented in Table 2.

\section{Discussion}

The morphological alignment of the cervical spine is an important issue due to potential clinical importance. The morphological classification may simplify the patients' assessment and improve understanding between therapeutic team in the treatment course. The description of the cervical spine based on the value of the cervical lordosis angle solely may obscure significant alignment disturbance. When one analyzes only a tilt of the two end vertebrae the local kyphosis or a decrease of the lordosis is easy to omit. The CL angle evaluation is more precise in the lordosis or the kyphosis spine alignment, but may be not sufficient in the straight or the sigmoid alignment of the cervical spine. On the other hand, the analysis of the relative rotation angle at each level (the angle between the line sustained by posterior margin of the vertebral bodies of the two adjacent vertebrae - measured with sagittal tangent method at five levels: $\mathrm{C} 2-\mathrm{C} 3, \mathrm{C} 3-\mathrm{C} 4, \mathrm{C} 4-\mathrm{C} 5, \mathrm{C} 5-\mathrm{C} 6, \mathrm{C} 6-\mathrm{C} 7)$ is complicated and is difficult to obtain full image of the cervical spine using this method [17]. It is rather assigned to the scientific analysis of local relationships than to the clinical use. Although, the cSVA is an important factor showing the translation between the $\mathrm{C} 2$ and $\mathrm{C} 7$ vertebrae, it may have similar limitations regardless the morphology of the cervical spine. In this study there was no difference in cSVA between the patients with SDT vs SDTL, while the differences in CL and cervical spine morphology classification were significant. When CL is considered in combination with cSVA it may provide more precise image of the cervical spine morphology. However, we believe that morphology classification of the cervical spine makes the image more obvious.

What is more, this study shows an important effect of the influence of the deformations of the distant segments of the spine on the cervical alignment, what is in line with published studies $[7,8,18,19]$. The type of SD has an important influence on the cervical spine morphology. The lordotic morphology of the cervical spine was found in most of patients with SDT (56\%) and only in one third of SDTL patients (34\%). Thus, the morphology of the cervical spine considered as physiological (lordosis) was much less common in SDTL patients. In this study the cervical lordosis was significantly bigger in SDT than in SDTL patients, what stays in-line with published studies $[7,8,18,19]$. Thus knowing the type of SD we may predict the morphology of the cervical spine. It is important issue because deterioration of the cervical sagittal balance has an importantclinical consequence. The worstmorphological alignment of the cervical spine seems to be the kyphosis and the sigmoid shape (with local kyphosis). The cervical kyphosis is associated with adverse consequences and problems [18,20]. Patients with the cervical kyphosis often present with neck pain [21]. One of the reasons of the neck pain may be the fact that cervical muscles are placed at a significant biomechanical stress and requires constant contraction to maintain an upright head posture and horizontal gaze $[20,22]$. The other reason of the neck pain may be excessive, accelerated degeneration of cervical intervertebral discs; however, this issue was described mostly in the adjacent segment disease evaluation $[18,20,23]$. The cervical kyphosis is postulated to play a substantial role in the development of cervical myelopathy. The 
deformity leads to compression of the spinal cord against the vertebral bodies and to the increasing longitudinal tension to the spinal cord due its tethering by the dentate ligaments and cervical nerve roots $[18,24]$. The radiculopathy is also a problem described in context of the kyphotic changes in the cervical alignment [21]. Taking into consideration results of this study we can assume that patties with SDTL are in higher risk of adverse consequences. This should be taken into consideration in the patients' follow-up evaluation and in the treatment planning.

The evaluated groups of SDT and SDTL had comparable age and gender. Even though, the percentage of females in the SDTL group seems to be higher ( $47.4 \%$ vs $33.3 \%$ ), however this difference was not statistically significant. The difference in the sagittal spine alignment parameters between the SDT and SDTL reveal typical changes between these groups and are in-line with published data $[7,8]$. To our knowledge this is the first study concerning the morphologic classification of the cervical spine alignment in SD. It shows the advantages of this classification. What is more it indicates the SDTL group of patients as a group with elevated risk of the disturbed cervical spine aliments. Limitation of this study is its retrospective design. The longitudinal studies showing the clinical importance of this finding would be of great value.

\section{Conclusion}

The type of the Scheuermann's disease has an impact on the cervical spine morphology. There is a higher tendency to the kyphotic and the sigmoid cervical spine alignment in the thoracolumbar type than in the thoracic type of Scheuermann disease.

\section{Conflict of Interest}

Authors declared no conflict of interest.

\section{References}

1. Lowe TG (2007) Scheuermann's kyphosis. Neurosurg Clin N Am 18: 305315.

2. Damborg F, Engell V, Nielsen J, Kyvik KO, Andersen MO, Thomsen K (2011) Genetic epidemiology of Scheuermann's disease. Acta Orthop 82(5): 602-605.

3. Palazzo C, Sailhan F, Revel M (2014) Scheuermann's disease: an update. Joint Bone Spine 81(3): 209-214.

4. Lowe TG, Line BG (2007) Evidence based medicine: analysis of Scheuermann kyphosis. Spine (Phila Pa 1976) 32(19): S115-119.

5. Wenger DR, Frick SL (1999) Scheuermann kyphosis. Spine 24: 26302639.

6. KH S (1964) Scheuermann's juvenile kyphosis: clinical appearances, radiography, aetiology and prognosised. Copenhagen, Munksgaard, Denmark.

7. Janusz P, Tyrakowski M, Kotwicki T, Siemionow K (2015) Cervical sagittal alignment in scheuermann disease. Spine (Phila Pa 1976) 40 (23): E1226-1232.
8. Jiang L, Qiu Y, Xu L, Liu Z, Wang Z, et al. (2014) Sagittal spinopelvic alignment in adolescents associated with Scheuermann's kyphosis: a comparison with normal population. Eur Spine J 23(7): 1420-1426.

9. Schwab F, Lafage V, Patel A, Farcy J-P (2009) Sagittal plane considerations and the pelvis in the adult patient. Spine 34(17): 1828-1833.

10. Roussouly P, Berthonnaud E, Roussouly D, Locard RE, Hospitalier C, et al. (2002) Sagittal morphology and equilibrium of pelvis and spine. Eur Spine J 11(1): 80-87.

11. Roussouly P, Pinheiro-Franco JL (2011) Biomechanical analysis of the spino-pelvic organization and adaptation in pathology. European Spine Journal 20 (Suppl 5): 609-618.

12. Boulay C, Tardieu C, Hecquet J, Benaim C, Mouilleseaux B, et al. (2006) Sagittal alignment of spine and pelvis regulated by pelvic incidence: standard values and prediction of lordosis. European Spine Journal 15(4): 415-422.

13. Le Huec JC, Saddiki R, Franke J, Rigal J, Aunoble S (2011) Equilibrium of the human body and the gravity line: the basics. European Spine Journal 20 (Suppl 5): 558-563.

14. Nasto LA, Shalabi ST, Perez-Romera AB, Muquit S, Ghasemi AR, et al. (2017) Analysis of cervical sagittal alignment change following correction of thoracic and thoracolumbar Scheuermann's kyphosis. Eur Spine J 26(8): 2187-2197.

15. Bradford DS (1977) Juvenile kyphosis. Clin Orthop Relat Res (128): 4555.

16. Ohara A, Miyamoto K, Naganawa T, Matsumoto K, Shimizu K (2006) Reliabilities of and correlations among five standard methods of assessing the sagittal alignment of the cervical spine. Spine 31(22): $2585-2591$

17. Harrison DE, Harrison DD, Cailliet R, Troyanovich SJ, Janik TJ, et al. (2000) Cobb method or Harrison posterior tangent method: which to choose for lateral cervical radiographic analysis. Spine (Phila Pa 1976) 25(16): 2072-2078.

18. Scheer JK, Tang JA, Smith JS, Acosta FL, Protopsaltis TS, et al. (2013) Cervical spine alignment, sagittal deformity, and clinical implications: a review. J Neurosurg Spine 19(2):141-159.

19. Lee SH, Son ES, Seo EM, Suk KS, Kim KT (2013) Factors determining cervical spine sagittal balance in asymptomatic adults: correlation with spinopelvic balance and thoracic inlet alignment. The Spine 15(4): 705712.

20. Han K, Lu C, Li J, Xiong GZ, Wang B, et al. (2011) Surgical treatment of cervical kyphosis. Eur Spine J 20(4): 523-536.

21. Ferch RD, Shad A, Cadoux-Hudson TA, Teddy PJ (2004) Anterior correction of cervical kyphotic deformity: effects on myelopathy, neck pain, and sagittal alignment. J Neurosurg 100: 13-19.

22. Munechika Y (1973) Influence of laminectomy on the stability of the spine: an experimental study with special reference to the extent of laminectomy and the resection of the intervertebral joint. J Jpn Orthop Assoc 47(111): 111-126.

23. Katsuura A, Hukuda S, Imanaka T, Miyamoto K, Kanemoto M (1996) Anterior cervical plate used in degenerative disease can maintain cervical lordosis. J Spinal Disord 9(6): 470-476.

24. Shimizu K, Nakamura M, Nishikawa Y, Hijikata S, Chiba K, et al. (2005) Spinal kyphosis causes demyelination and neuronal loss in the spinal cord: a new model of kyphotic deformity using juvenile Japanese small game fowls. Spine (Phila Pa 1976) 30(21): 2388-2392. 
Creative Commons Attribution 4.0 International License

For possible submissions Click Here

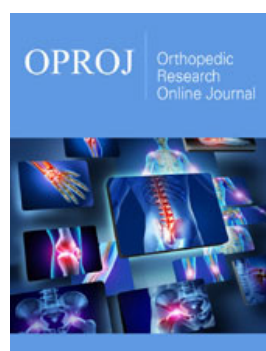

Orthopedic Research Online Journal

\section{Benefits of Publishing with us}

- High-level peer review and editorial services

- Freely accessible online immediately upon publication

- Authors retain the copyright to their work

- Licensing it under a Creative Commons license

- Visibility through different online platforms 